Check for updates

Cite this: RSC Adv., 2018, 8, 14479

\title{
Revealing unusual rigid diamond net analogues in superhard titanium carbides $\dagger$
}

\author{
Chunhong Xu, Kuo Bao, Shuailing Ma, Da Li, (D) Defang Duan, Hongyu Yu, \\ Xilian Jin, (D) Fubo Tian, Bingbing Liu (D) and Tian Cui (D)*
}

Transition metal carbides (TMCS) are considered to be potential superhard materials and have attracted much attention. With respect to titanium and carbon atoms, we confirm the pressure-composition phase diagram of the $\mathrm{Ti}-\mathrm{C}$ system using structure searches and first-principles calculations. We firstly discovered stable $\mathrm{TiC}_{4}$ which was expected to be synthesized at high pressure, as well as metastable $\mathrm{TiC}_{2}$ and $\mathrm{TiC}_{3}$. These layered titanium carbides are diamond net analogues due to the unusual $\mathrm{C}$-layers in the form of puckered graphene-like, diamond-like and double diamond-like C-layers. The existence of diamond-like $\mathrm{C}$-layers might help to understand the formation of diamond. All the studied titanium carbides could be recoverable at ambient pressure and exhibited great mechanical properties (strong ability to resist volume and shear deformations, small anisotropy, and high hardness). Moreover, we crystallized the structure of $\mathrm{TiC}_{4}$ in other transition metal carbides and obtained five superhard $\mathrm{TMC}_{4} \mathrm{~S}$ ( $\mathrm{TM}=\mathrm{V}, \mathrm{Zr}, \mathrm{Nb}, \mathrm{Hf}$ and $\mathrm{Ta}$ ). Interactions between layers were revealed to be the source of the great mechanical properties and high hardness through combining detailed analyses of electronic structure and chemical bonding, namely, weak ionic interactions of neighboring $\mathrm{Ti}$ - and $\mathrm{C}$-layers and the strong covalent interactions of $\mathrm{C}$ - and $\mathrm{C}$-layers.

Received 14th January 2018

Accepted 25th March 2018

DOI: $10.1039 / \mathrm{c} 8 \mathrm{ra00400e}$

rsc.li/rsc-advances and carbon $\left(2 \mathrm{~s}^{2} 2 \mathrm{p}^{2}\right)$ atoms, which would be beneficial to mechanical properties of titanium carbides. The hardness of titanium carbide compounds is closely related to chemical bonding. There are three bonding behaviors present in principle, viz., metallic Ti-Ti bonds, strong covalent $\mathrm{C}-\mathrm{C}$ bonds and partial ionic Ti-C bonds. Short and covalent $\mathrm{C}-\mathrm{C}$ bonds are the most important factor contributing to high hardness. Second are partially ionic $\mathrm{Ti}-\mathrm{C}$ bonds. Metallic $\mathrm{Ti}-\mathrm{Ti}$ bonds can introduce dislocation mobility; this is harmful for hardness. Thus the improvement of hardness can strengthen $\mathrm{C}-\mathrm{C}$ and $\mathrm{Ti}-\mathrm{C}$ interactions, and eliminate direct $\mathrm{Ti}-\mathrm{Ti}$ interactions. Most hard $\mathrm{TiC}_{n}(n<1)$ compounds have been synthesized and studied widely. ${ }^{16-29}$ Their high hardness only derives from partially ionic Ti-C bonds. In this work, we take full advantage of this strong $\mathrm{Ti}-\mathrm{C}$ interaction, and simultaneously introduce a $\mathrm{C}-\mathrm{C}$ interaction to obtain novel titanium carbides. As is known to all, high pressure can cause profound changes in the electronic orbitals and bonding behaviors, which brings about many unusual hard multifunctional materials, ${ }^{\mathbf{3 0}-32}$ and may become an important technique to realize our idea.

Here, based on USPEX simulations, the phase diagram of titanium carbides has been established at the pressure range of 0-100 GPa. New high pressure phases of diamond net analogue titanium carbides $\left(\mathrm{TiC}_{2}, \mathrm{TiC}_{3}\right.$ and $\left.\mathrm{TiC}_{4}\right)$ are proposed and can stabilize dynamically at ambient pressure. Their structural stability and mechanical properties are discussed and correlated with electronic structures and chemical bonding. The
State Key Laboratory of Superhard Materials, College of Physics, Jilin University, Changchun 130012, China. E-mail: cuitian@jlu.edu.cn; baokuo@jlu.edu.cn; Fax: +86-431-85168825; Tel: +86-431-85168825

$\dagger$ Electronic supplementary information (ESI) available. See DOI: 10.1039/c8ra00400e 
results show that interlayer interactions are responsible for great mechanical properties and high hardness in all of the studied titanium carbides.

\section{Computational details}

We used the universal structure predictor USPEX, ${ }^{33-35}$ interfaced with the VASP code, to explore the new titanium carbides. These simulations, for all considered stoichiometries $(8: 7,8: 5,6: 5$, $5: 4,5: 3,4: 3,3: 2,2: 1,1: 1,1: 2,1: 3$, and $1: 4)$, were performed at pressures of $0-100 \mathrm{GPa}$. The total energy calculations and local structural relaxations were carried out within the generalized gradient approximation and the exchangecorrelation functional of Perdew, Burke and Ernzerhof. ${ }^{36}$ We described the interactions between the ions and the electrons by using the pseudo-potential plane-wave method. The electronic configurations of titanium, zirconium, hafnium, vanadium, niobium, tantalum and carbon are Ti: $3 \mathrm{p}^{6} 3 \mathrm{~d}^{3} 4 \mathrm{~s}^{1}, \mathrm{~V}$ : $3 \mathrm{p}^{6} 3 \mathrm{~d}^{4} 4 \mathrm{~s}^{1}$, Zr: $4 \mathrm{~s}^{2} 4 \mathrm{p}^{6} 5 \mathrm{~s}^{2} 4 \mathrm{~d}^{2}$, Nb: $4 \mathrm{p}^{6} 5 \mathrm{~s}^{1} 4 \mathrm{~d}^{4}$, Hf: $5 \mathrm{p}^{6} 6 \mathrm{~s}^{2} 5 \mathrm{~d}^{2}$, Ta: $5 \mathrm{p}^{6} 6 \mathrm{~s}^{2} 5 \mathrm{~d}^{3}$, and C: $2 \mathrm{~s}^{2} 2 \mathrm{p}^{2}$. The tested cutoff energy of $850 \mathrm{eV}$ and the Monkhorst-Pack $k$-point meshes with a grid of $2 \pi \times 0.03$ $\AA^{-1}$ were chosen to achieve a total energy convergence of less than $1 \mathrm{meV}$ per atom. To verify the mechanical and dynamical stabilities of the predicted structures, we calculated elastic constants and the phonon using the strain-stress method and a supercell approach ${ }^{37}$ implemented in the PHONOPY code, ${ }^{38}$ respectively. The mechanically stable structures should satisfy the generalized elastic stability criteria. ${ }^{39}$ The bulk modulus $B$, shear modulus $G$, Young's modulus $Y, B / G$ and Poisson's ratio $\nu$ were estimated via the Voigt-Reuss-Hill (VRH) approximations. ${ }^{40}$ The theoretical Vickers hardness was estimated by using Gao's model. ${ }^{41}$ The Mulliken bond population was calculated via the supercell method with the CASTEP code. ${ }^{\mathbf{4 2 , 4 3}}$ The ultrasoft Vanderbilt pseudo-potential (USPP) ${ }^{\mathbf{4 4}}$ with PBE-GGA was chosen. The cutoff energy and k-mesh were same as the setting in VASP calculations. The Reflex Tools of Materials Studio code was used to simulate the X-ray diffraction data. ${ }^{45}$ The Ti-C bonding information is analyzed by calculating the crystal orbital Hamilton population (COHP). The calculation is based on the PW method, and is performed by re-extracting atomresolved information from the delocalized PW basis sets, which is named "projected COHP" (pCOHP). ${ }^{\mathbf{4 6 , 4 7}}$

\section{Results and discussion}

We have used the $a b$ initio evolutionary algorithm USPEX to explore the Ti-C system. In this paper, we only discuss $\operatorname{TiC}_{n}(n \geq$ 1) compounds; other $\operatorname{TiC}_{n}(n<1)$ phases will be discussed in other papers. By evaluating the formation enthalpy $\Delta H$ for each composition at $0 \mathrm{~K}$ and different pressures, the convex hull at different pressures is obtained (Fig. 1). Hexagonal titanium metal $(\alpha-\mathrm{Ti})^{48}$ and graphite were used as reference structures. In Fig. 1a, TiC has a stable composition for all considered pressures. However, metastable phases of $\mathrm{TiC}_{2}$ and $\mathrm{TiC}_{3}$ are energetically favorable above $60 \mathrm{GPa}$ and deserve to be studied. Fortunately, we found a stable high-pressure phase of $\mathrm{TiC}_{4}$ located on the convex hull in the pressure range of 60-100 GPa
(Fig. 1b) for the first time. The ground state configurations of $\mathrm{Ti}_{2} \mathrm{C}, \mathrm{Ti}_{3} \mathrm{C}_{2}, \mathrm{Ti}_{6} \mathrm{C}_{5}$ and $\mathrm{TiC}$ are in good agreement with preexisting theoretical ${ }^{25,27,49}$ and experimental results. ${ }^{21,50}$ Furthermore, the simulated X-ray diffraction of cubic structures of $\mathrm{Ti}_{2} \mathrm{C}^{51}$ and $\mathrm{TiC}^{52}$ is in accordance with experimental results (Fig. S1†). These results suggest our methodology is credible. The crystallographic parameters of $\mathrm{Ti}_{2} \mathrm{C}, \mathrm{Ti}_{3} \mathrm{C}_{2}, \mathrm{Ti}_{6} \mathrm{C}_{5}$, and TiC$\mathrm{TiC}_{4}$ are listed in Table S1. $\dagger$ Fig. 2 shows the crystal structures of TiC- $\mathrm{TiC}_{4}$. In the predicted structures, the rock-salt-type TiC (SG: $F m \overline{3} \mathrm{~m}$ ) consists of Ti-C bonds (Fig. 2a). The Ti-C bond length of $2.168 \AA$ is in good agreement with the experimental value of $2.164 \AA$ A. Interestingly, three unusual diamond net analogues with various C-layers were plainly observed in $\operatorname{TiC}_{n}(n>1)$ compounds. In the trigonal $\mathrm{TiC}_{2}(\mathrm{SG}: R \overline{3} \mathrm{~m}$ ) structure, the puckered graphene-like C-layers are separated by Ti-layers (Fig. 2b). The $\mathrm{C}-\mathrm{C}$ bond length is $1.600 \AA$, which is smaller than that of $\mathrm{RhN}_{2}-\mathrm{OsC}_{2}(1.242 \AA) .{ }^{53}$ What is more, the introduction of the puckered graphene-like C-layers can cause the quasi-3D effect, which usually emerges in transition metal borides, ${ }^{54}$ but has for the first time been obtained in transition metal carbides. The $\mathrm{TiC}_{3}$ structure (SG: $R \overline{3} \mathrm{~m}$ ) has one type of $\mathrm{Ti}$ atom and three types of $\mathrm{C}$ atom. Its lattice parameter $c(30.670$ $\AA$ ) is so long that we have only presented its partial structure. In Fig. 2c, each $\mathrm{C} 1$ atom is coordinated with four $\mathrm{C}$ atoms, including three $\mathrm{C} 3$ atoms stabilized in a plane and one $\mathrm{C} 1$ atom, forming diamond-like C-layers along the $c$-axis. The puckered graphene-like C-layers between two Ti-layers consist of shared $\mathrm{C} 1$ atoms and $\mathrm{C} 3$ atoms, and bridge the diamond-like C-layers. The bond lengths of C1-C1, C1-C3 and C2-C2 are $1.586 \AA$, 1.584 $\AA$ and $1.567 \AA$, respectively. These $\mathrm{C}-\mathrm{C}$ lengths are similar to those of $\mathrm{RuC}_{2}$ (ref. 55) and $\mathrm{OsC}_{2} \cdot{ }^{53,55,56}$ The shortest $\mathrm{C}-\mathrm{C}$ bond length is comparable to that in diamond (1.544 $\AA$ ). With an additional $\mathrm{C}$ atom in the lattice, there is one type of $\mathrm{Ti}$ atom and four types of $\mathrm{C}$ atom in the structure of $\mathrm{TiC}_{4}(\mathrm{SG}: P \overline{3} m 1)$. The bonding environment within $\mathrm{TiC}_{4}$ is similar to that of $\mathrm{TiC}_{3}$, namely, C1 atoms construct the puckered graphene-like Clayers, and C2, C3 and C4 atoms construct the double diamond-like C-layers, and bridge the puckered graphene-like C-layers. These C-layers sandwich two Ti-layers (see Fig. 2d). In comparison to $\mathrm{TiC}_{3}$, the different $\mathrm{C}-\mathrm{C}$ bond lengths in $\mathrm{TiC}_{4}$ $(\mathrm{C} 1-\mathrm{C} 1=1.559 \AA$, $\mathrm{C} 2-\mathrm{C} 2=1.576 \AA$, $\mathrm{C} 2-\mathrm{C} 3=1.560 \AA$ and $\mathrm{C} 3-$ $\mathrm{C} 4=1.581 \AA$ ) are closer to those of diamond. Diamond-like Clayers have been reported in $\mathrm{Ru}-\mathrm{C}$ and Os-C systems; ${ }^{53,55,56}$ here for the first time they appear in the thermodynamically stable phases of $\mathrm{TiC}_{3}$ and $\mathrm{TiC}_{4}$. Thus, these new titanium carbides can be considered as diamond net analogues due to the unusual Clayers along the $c$-axis. These titanium carbides may exhibit the characteristics of diamond, that is to say, they may possess excellent mechanical properties and high hardness. With unusual C-layers in $\operatorname{TiC}_{n}(n>1)$ compounds, when $n=2$, the puckered graphene-like C-layers appear in titanium carbides; when $n \geq 3$, titanium carbides begin to exhibit single and double diamond-like C-layers; when $n \sim \infty$, there is a reasonable assumption of obtaining pure diamonds, where transition metal $\mathrm{Ti}$ atoms are the catalyst components, similar to the powerful elemental catalysts $\mathrm{Co}, \mathrm{Fe}, \mathrm{Mn}, \mathrm{Nr}$ and $\mathrm{Cr}$ which are used to synthesize diamond under high pressure. ${ }^{57}$ This can 

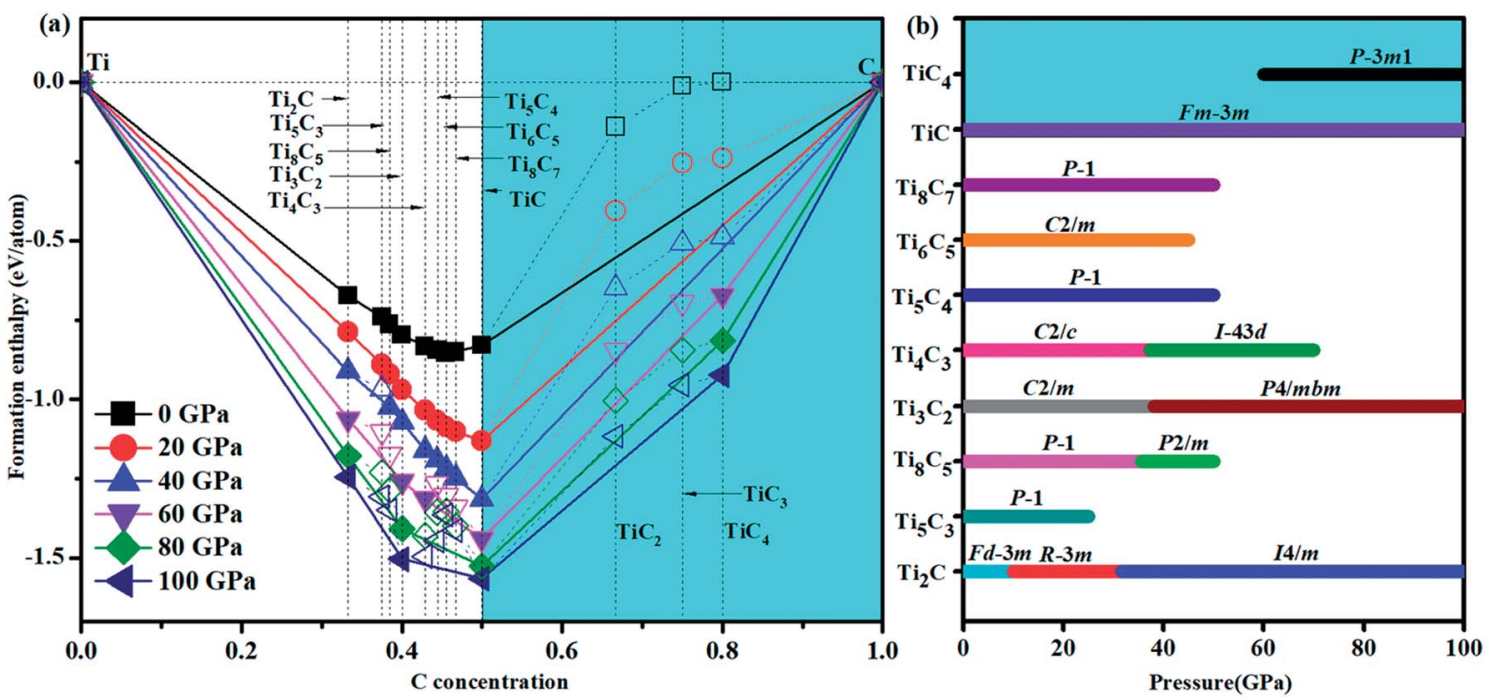

Fig. 1 (a) Convex hull of the Ti-C system. The convex hulls connecting stable phases (solid shapes) are shown by solid lines. Metastable phases (open shapes) are shown by dashed lines. (b) Pressure-composition phase diagram of the Ti-C system. The stable TiC $n(n \geq 1)$ phases are highlighted by cyan shadows.

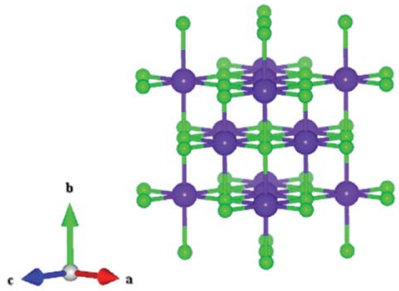

(a)

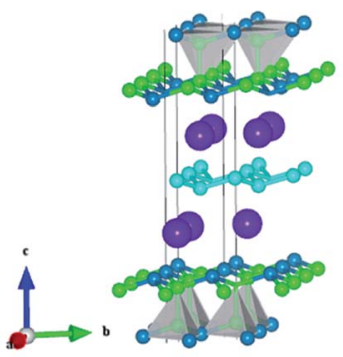

(c)
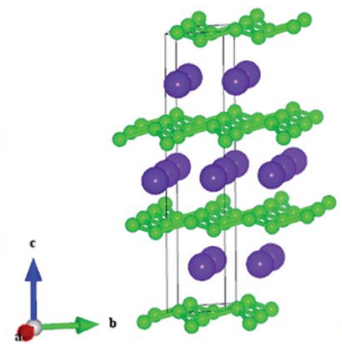

(b)
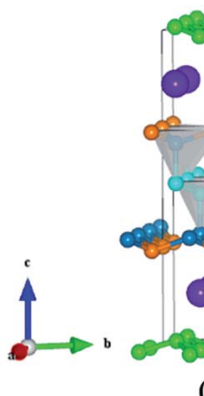

(d)
Fig. 2 Crystal structures of titanium carbides. (a) TiC (SG: Fm3m), (b) $\mathrm{TiC}_{2}$ (SG: $R 3 \mathrm{~m}$ ), (c) the partial structure of $\mathrm{TiC}_{3}$ (SG: $R 3 \mathrm{~m}$ ) and (d) $\mathrm{TiC}_{4}$ (SG: $P 3 m 1$ ). The big balls represent titanium atoms, and the small balls represent carbon atoms.

widen the understanding and production of diamond. In Fig. S2, $\uparrow$ there are no imaginary frequencies in the whole Brillouin zone of all new phases for titanium carbides at 0 and $100 \mathrm{GPa}$, indicating that all the studied high pressure phases in titanium carbides could be quenchable under ambient conditions.

For materials, the useful information of mechanical properties and hardness can be obtained from accurate elastic constants. To test the mechanical stability of the studied titanium carbides, we calculated their elastic constants using the strain-stress method. These results are listed in Table 1. Based on the elastic constants, the obtained bulk modulus $B$, shear modulus $G$, Young's modulus $Y, B / G$, and Poisson's ratio $\nu$ are tabulated in Table 1. For comparison, the elastic properties of diamond have been calculated. According to our calculated results, all elastic constants meet the mechanical stability criteria, ${ }^{39}$ which indicates their elastic stability. The calculated elastic constants of TiC and diamond are in excellent agreement with the experiment values, ${ }^{58,59}$ suggesting the credibility of our calculations. Among these titanium carbides, $\mathrm{TiC}_{4}$ has the highest $\mathrm{C}_{11}$ value of $844 \mathrm{GPa}$ due to the shortest $\mathrm{C} 1-\mathrm{C} 1$ bond $(1.559 \AA)$ in the puckered graphene-like C-layers, similar to that of $\mathrm{OsC}_{4}(866 \mathrm{GPa})^{53}$ and larger than that of $\mathrm{RuC}_{4}(610 \mathrm{GPa}),{ }^{55}$ indicating a strong ability to resist elastic deformation in $\mathrm{TiC}_{4}$ along the $a$-axis. From $\mathrm{TiC}$ to $\mathrm{TiC}_{4}$, the increasingly large values of $\mathrm{C}_{33}$ indicate that they are difficult to compress along the $c$ axis. Moreover, the $\mathrm{C}_{11}$ and $\mathrm{C}_{33}$ values of $\mathrm{TiC}_{3}$ are larger by $17.7 \%$ and $9.8 \%$ than those of $\mathrm{TiC}_{2}$, respectively. This shows the evident influence of the puckered graphene-like C-layer and diamond-like C-layer. The shear constants of $\mathrm{C}_{44}$ range from $255 \mathrm{GPa}$ to $302 \mathrm{GPa}$ in $\mathrm{TiC}_{n}(n>1)$ compounds, which are larger than those of $\mathrm{RuC}_{2}-\mathrm{RuC}_{4}$ (below $200 \mathrm{GPa}$ ), ${ }^{55}$ suggesting these $\mathrm{TiC}_{n}(n>1)$ compounds may possess strong shear strength and high hardness.

The bulk modulus and shear modulus quantify the ability to resist volume, shear and tension changes. The values of bulk moduli for $\mathrm{TiC}_{3}(317 \mathrm{GPa})$ and $\mathrm{TiC}_{4}(332 \mathrm{GPa})$ are greater than $300 \mathrm{GPa}$, indicating their better ability to resist volume deformation. It is widely believed that hardness has a closer relation to shear modulus than bulk modulus. $\mathrm{TiC}_{3}$ and $\mathrm{TiC}_{4}$ possess relatively larger shear moduli of $297 \mathrm{GPa}$ and $326 \mathrm{GPa}$, which are larger than those of $\mathrm{RuC}_{4}$ (ref. 55) and $\mathrm{OsC}_{4}{ }^{.53,55,56}$ Furthermore, Poisson's ratio can describe the degree of directionality of 
Table 1 Calculated elastic constants $C_{i j}(\mathrm{GPa})$, bulk modulus $B(\mathrm{GPa})$, shear modulus $G(\mathrm{GPa})$, Young's modulus $Y(\mathrm{GPa}), B / G$ and Poisson's ratio $\nu$ for $\operatorname{TiC}_{n}(n>1)$ compounds

\begin{tabular}{|c|c|c|c|c|c|c|c|c|c|c|c|c|}
\hline & Phase & $C_{11}$ & $C_{33}$ & $C_{44}$ & $C_{66}$ & $C_{12}$ & $C_{13}$ & $B$ & $G$ & $B / G$ & $Y$ & $\nu$ \\
\hline \multirow[t]{2}{*}{ TiC } & $F m \overline{3} m$ & 515 & & 167 & & 120 & & 252 & 178 & 1.41 & 433 & 0.21 \\
\hline & Exp & 513 (ref. 58) & & 178 (ref. 58) & & 106 (ref. 58) & & 240 (ref. 58) & & & & \\
\hline $\mathrm{TiC}_{3}$ & $R \overline{3} m$ & 785 & 602 & 280 & 326 & 133 & 110 & 317 & 297 & 1.07 & 679 & 0.14 \\
\hline $\mathrm{TiC}_{4}$ & $P \overline{3} m 1$ & 844 & 664 & 302 & 362 & 120 & 105 & 332 & 326 & 1.02 & 738 & 0.13 \\
\hline Diamond & $F m \overline{3} m$ & 1054 & & 562 & & 125 & & 435 & 520 & 0.84 & 1116 & 0.07 \\
\hline
\end{tabular}

covalent bonding. Low Poisson's ratio $(\sim 0.2)$ materials often have strong covalence. Specifically, $\mathrm{TiC}_{3}$ and $\mathrm{TiC}_{4}$ possess the lowest Poisson's ratio (0.14 and 0.13 ) for known transition metal carbides. ${ }^{53,55,56} \mathrm{~A} B / G$ ratio value higher (lower) than 1.75 indicates the material is ductile (brittle). All these titanium carbides have $B / G$ values smaller than 1.75 , suggesting their brittle nature. It is not hard to see that high elastic constants and moduli, and small Poisson's ratios and $B / G$ values, imply great mechanical properties and the potential possibility of titanium carbides becoming hard or superhard materials. The elastic anisotropy is highly related with the microcracks in materials. ${ }^{60}$ So we quantitatively calculated anisotropic properties using the ElAM (Elastic Anisotropy Measures) code. ${ }^{61}$ As an example, the result of $\mathrm{TiC}_{2}$ is shown in Fig. 3, and the others are included in Fig. S3-S5. $\dagger$ For a real material, the threedimensional directional dependence exhibits a perfect spherical shape. The deviation degree from the spherical shape reflects the amount of anisotropy. According to our simulated results, they all exhibit small elastic anisotropy, which is favorable to their mechanical properties and hardness.

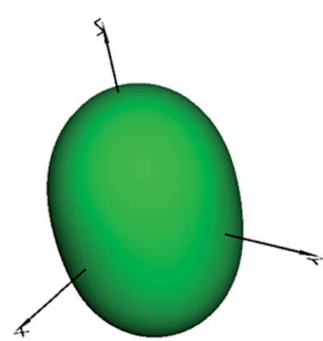

(a) Linear compressibility

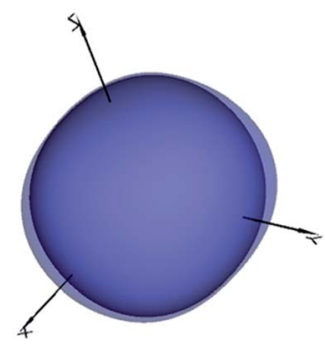

(c) Shear ratio

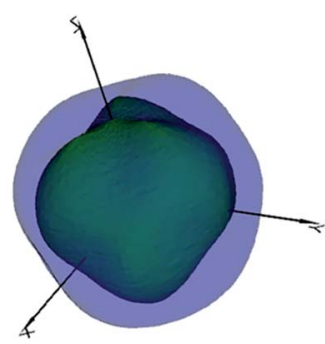

(b) Poisson's ratio

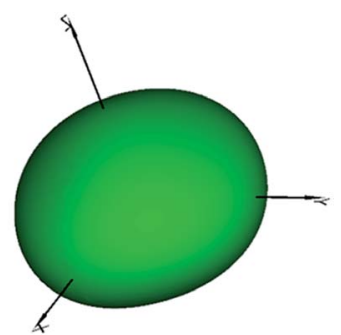

(d) Young's modulus
Fig. 3 The calculated three-dimensional representations of (a) linear compressibility, (b) Poisson's ratio, (c) shear ratio, and (d) Young's modulus for the $\mathrm{TiC}_{2}$ structure.

\section{Hardness}

In order to verify our hypothesis of the intrinsic hardness, we calculated the hardness of these titanium carbides by using Gao's model ${ }^{41}$ which includes the role of the metallic bond to evaluate intrinsic hardness. The expressions and detailed parametric descriptions of the complex transition metal compounds have been previously reported in ref. 62 . Using this formula, the related bond parameters and hardness values of diamond and the titanium carbides are listed in Table 2. Our calculated Vickers hardness values of diamond and TiC agree well with experimental data, ${ }^{63,64}$ demonstrating the reliability of the hardness model we have used. The obtained hardness values of $\mathrm{TiC}, \mathrm{TiC}_{2}, \mathrm{TiC}_{3}$ and $\mathrm{TiC}_{4}$ are 32.7, 32.4, 40.8 and 49.1 $\mathrm{GPa}$, respectively. TiC and $\mathrm{TiC}_{2}$ could be classified as potential hard materials, while $\mathrm{TiC}_{3}$ and $\mathrm{TiC}_{4}$ are potential superhard materials. Based on the predicted stable $\mathrm{TiC}_{4}$, we constructed five $\mathrm{TMC}_{4}(\mathrm{TM}=\mathrm{V}, \mathrm{Zr}, \mathrm{Nb}, \mathrm{Hf}$ and $\mathrm{Ta})$ structures, and also calculated their mechanical properties and hardness. These structures are reasonable in terms of their thermodynamical, mechanical and dynamical stabilities, which are shown in Tables S2, S3 and Fig. S6. $\dagger$ Their optimized lattice parameters and atomic coordinates at ambient pressure are listed in Table S4. $\uparrow$ The related bond parameters of these $\mathrm{TMC}_{4}$ structures are listed in Table S5. $\dagger$ Using the same hardness model, the obtained Vickers hardness of $\mathrm{VC}_{4}, \mathrm{ZrC}_{4}, \mathrm{NbC}_{4}, \mathrm{HfC}_{4}$, and $\mathrm{TaC}_{4}$ are $50.3 \mathrm{GPa}, 41.9 \mathrm{GPa}, 43.9 \mathrm{GPa}, 49.3 \mathrm{GPa}$, and $59.2 \mathrm{GPa}$, respectively. Therefore, these new $\mathrm{TMC}_{4}$ compounds are potential superhard materials and have great mechanical properties, which could broaden the range of promising superhard materials.

\section{Electronic structures and chemical bonding}

The desire to explore the mechanism of the great mechanical properties and high hardness from the perspective of interlayer interactions motivates us to analyze the electronic structure and chemical bonding of titanium carbides, viz., the total and partial density of states (DOS), the crystal orbital Hamilton population (COHP), Bader charge, ${ }^{65}$ and the electron localization function (ELF) ${ }^{66}$ All four structures are metals due to their finite DOS at the Fermi level, which mainly originates from the high electron occupations in the Ti 3d orbitals as seen in Fig. 4. There are pronounced pseudogaps (a sharp valley around the Fermi level to divide the bonding and antibonding states) in their DOSs. The small electronegativity difference between $\mathrm{Ti}$ 
Table 2 Calculated bond parameters and Vickers hardness of titanium carbides

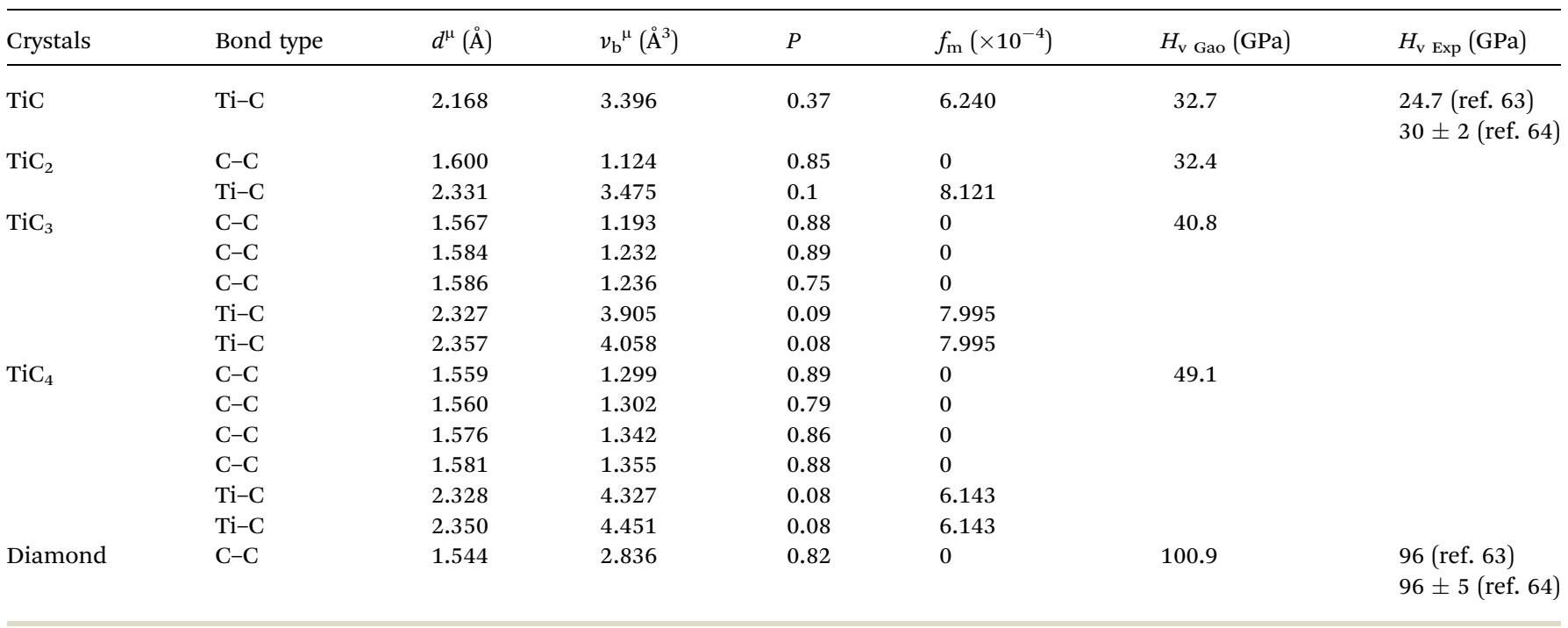
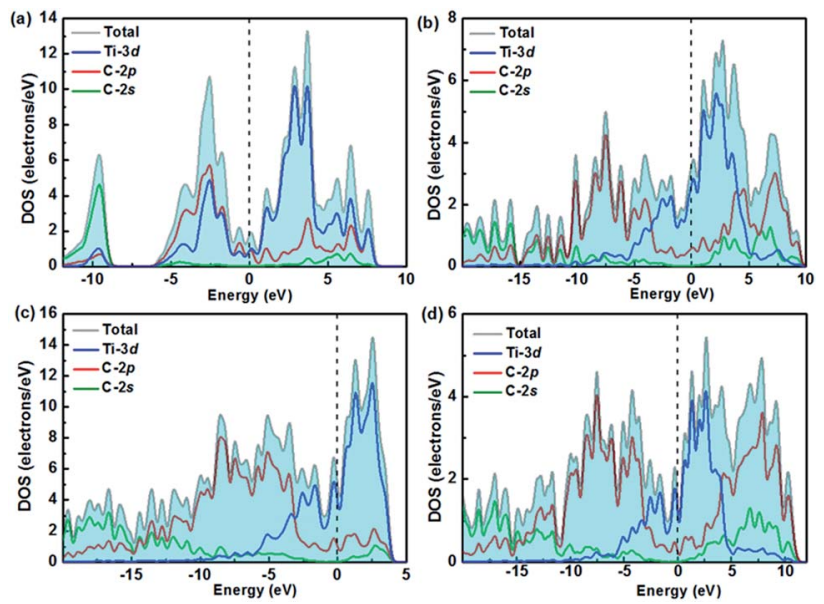

Fig. 4 Calculated total and partial densities of states for (a) TiC, (b) $\mathrm{TiC}_{2}$, (c) $\mathrm{TiC}_{3}$, and (d) $\mathrm{TiC}_{4}$.

(1.5) and C (2.5) atoms suggest hybridization effects, leading to the formation of pseudogaps, ${ }^{67}$ which will surely increase the stability of the compounds.

The DOS profiles in the energy range below $-10 \mathrm{eV}$ show nearly pure-carbon regions which correspond to strong $\mathrm{C}-\mathrm{C}$ interactions. Crystal orbital Hamilton population (COHP) can be used to understand the bonding/antibonding states of metals and nonmetals from the point of view of bonding energy. Fig. 5 shows the results of -pCOHP as a function of energy for different Ti-C bonds (corresponding to those in Table S6 + ) for TiC-TiC 4 . The negative contributions to the right represent bonding energy regions and positive to the left represent antibonding energy regions. According to Fig. 5, the (nearly) fullfilling of the $\mathrm{Ti}-\mathrm{C}$ bonding and antibonding states suggest the formation of strong $\mathrm{Ti}-\mathrm{C}$ bonding. The integrated crystal orbital Hamilton population (ICOHP) values of different $\mathrm{Ti}-\mathrm{C}$ and $\mathrm{C}-\mathrm{C}$ bonds, which is a quantitative evaluation of bonding strength, were calculated and are listed in Table S6. $\dagger$ From the -ICOHP values it can be concluded that the strongest $\mathrm{Ti}-\mathrm{C}$ interaction occurs in TiC. TiC has the shortest bond length of $2.168 \AA$ and the largest -ICOHP value of $2.99 \mathrm{eV}$. For other titanium carbide compounds, most -ICOHP values decrease with a more extended bond length of $\mathrm{Ti}-\mathrm{C}$, suggesting weaker bond strength. To further determine the nature of $\mathrm{Ti}-\mathrm{C}$ and $\mathrm{C}-\mathrm{C}$ bonding of the titanium carbides, the ELFs in the specific plane (110) have been calculated and are shown in Fig. 6. There being hardly any electron localization and moderate charge transfer between $\mathrm{Ti}$ and $\mathrm{C}$ atoms reflects the partially ionic $\mathrm{Ti}-\mathrm{C}$ bonding. Hence, one can see that the interactions of the neighboring Ti- and C-layers are still partially ionic, which inevitably induces slippage on the layers and harms the hardness. However, charge transfer for $\mathrm{TiC}_{2}, \mathrm{TiC}_{3}$ and $\mathrm{TiC}_{4}$ gradually diminishes (Table $\mathrm{S} 7 \dagger$ ), demonstrating the gradually decreasing ionicity of Ti- and and C-layers. This is in agreement with the changes in -COHP values between Ti and $\mathrm{C}$ atoms. According to Fig. $6 \mathrm{~d}$, $\mathrm{f}$ and $\mathrm{h}$, it is clearly seen that the electron density is mainly located at the center of $\mathrm{C}-\mathrm{C}$ bonds, mirroring strong covalent bonding. Especially for $\mathrm{TiC}_{3}$ and $\mathrm{TiC}_{4}$, electronic channels are formed by $\mathrm{C}$ atoms along the [110] direction. These results may explain the high values of shear moduli and incompressibility. In one puckered graphene-like C-layer, each $\mathrm{C}$ atom has one electron lone pair and three $\mathrm{C}-\mathrm{C}$ bonds resembling a diamond unit, without delocalized $\pi$ bonds (Fig. 6c). There is obviously $\mathrm{sp}^{3}$ hybridization of $\mathrm{C}$ atoms. The $\mathrm{C} 1$ atoms in $\mathrm{TiC}_{3}$ and the $\mathrm{C} 2$ and $\mathrm{C} 3$ atoms in $\mathrm{TiC}_{4}$ all formed tetrahedral $\mathrm{C}-\mathrm{C}$ bonds (Fig. 6e and $\mathrm{g}$ ), which is characterized by typical $\mathrm{sp}^{3}$ hybridization, leading to the formation of a diamond-like C-layer. The calculated large -ICOHP values between $\mathrm{C}-\mathrm{C}$ atoms also support strong covalent bonding between $\mathrm{C}$ atoms. These strong covalent $\mathrm{C}$ - and C-layers contribute towards titanium carbides becoming diamond net analogues. In a word, the weak ionic interactions of neighboring Ti- and C-layers and the strong covalent interactions of 


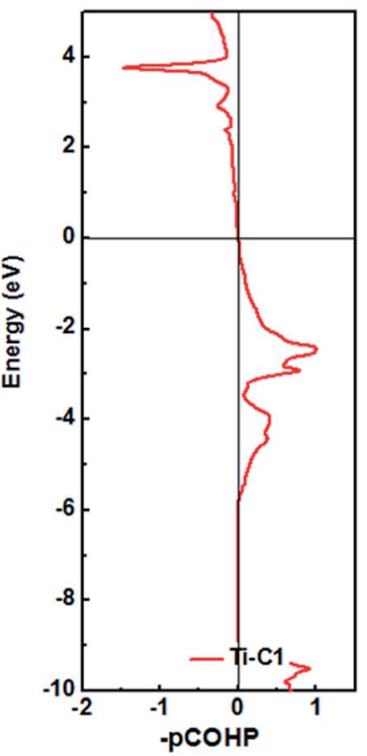

(a)

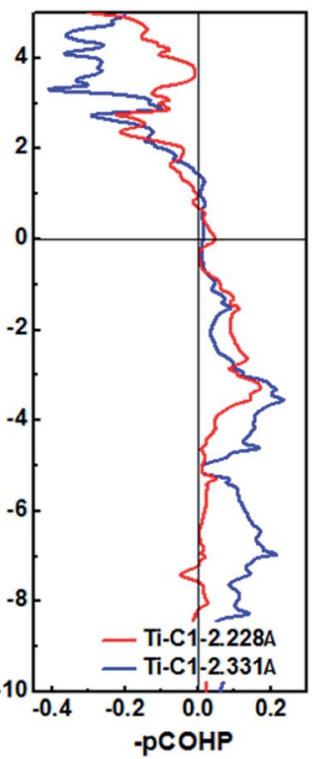

(b)

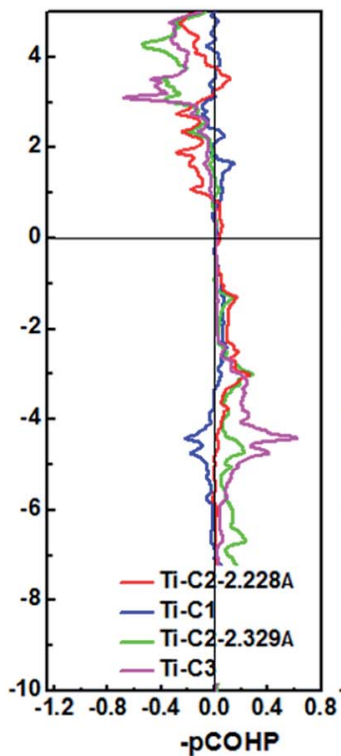

(c)

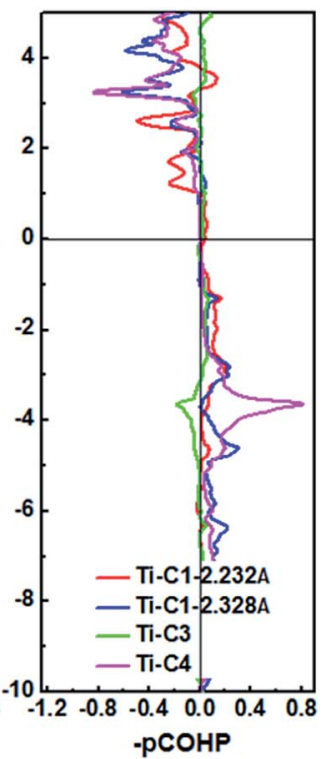

(d)

Fig. 5 Plots of the Crystal Orbital Hamilton Population (COHP) for (a) TiC, (b) $\mathrm{TiC}_{2}$, (c) $\mathrm{TiC}_{3}$ and (d) $\mathrm{TiC}_{4}$ using the pCOHP method. The horizontal line at zero is the Fermi level.

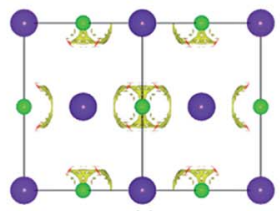

(a)

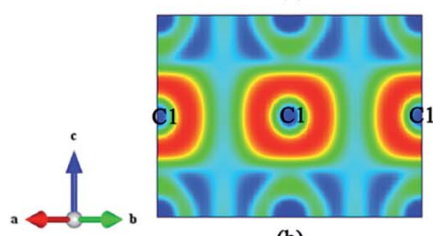

(b)

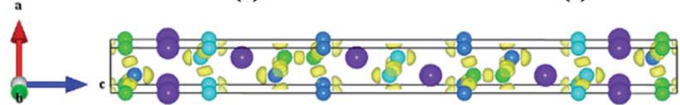

(e)

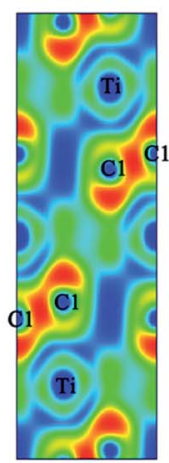

(d)

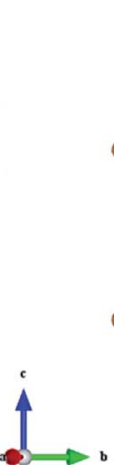

C3

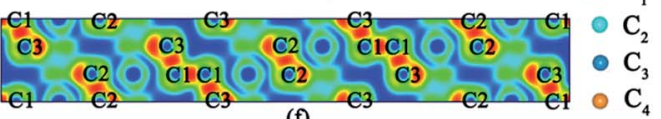

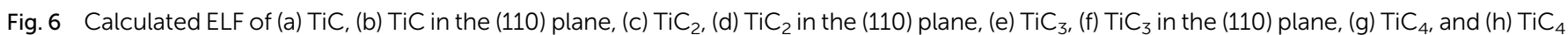
in the (110) plane. The calculated ELF isosurface is 0.8 .

C- and C-layers may be firstly used to explain the great mechanical properties and high hardness of these layered titanium carbides.

\section{Conclusions}

In summary, we first proposed layered titanium carbides and obtained a phase diagram under high pressure using structure searches and first-principles calculations, for metastable $\mathrm{TiC}_{2}$ and $\mathrm{TiC}_{3}$, and stable $\mathrm{TiC}_{4}$. The novel $\mathrm{TiC}_{4}$ was located on the convex hull and would be easy to synthesize in experiment. These predicted titanium carbides are diamond net analogues due to different C-layers. The appearance of diamond-like
C-layers enhances the formation and understanding of diamond. These titanium carbides all have great mechanical properties. The estimated values of hardness indicate that $\mathrm{TiC}$ and $\mathrm{TiC}_{2}$ are potential hard materials, and that $\mathrm{TiC}_{3}$ and $\mathrm{TiC}_{4}$ are potential superhard materials. By replacing the $\mathrm{Ti}$ atom in the structure of $\mathrm{TiC}_{4}$, we obtained five potential superhard $\mathrm{TMC}_{4}(\mathrm{TM}=\mathrm{V}, \mathrm{Zr}, \mathrm{Nb}, \mathrm{Hf}$ and $\mathrm{Ta})$ compounds and extended the opportunities of finding novel superhard materials. The calculated results of electronic structures and chemical bonding were analyzed to determine the nature of the interlayer interactions. Furthermore, the weak ionic interactions of neighboring Ti- and C-layers, and the strong covalent interactions of C- and C-layers are firstly used to explain the great mechanical properties and 
high hardness of these layered titanium carbides. We hope our results will provide guidance for further confirmatory research under high pressure, which is very useful to further explore new hard or superhard materials.

\section{Conflicts of interest}

There are no conflicts to declare.

\section{Acknowledgements}

This work was supported by the National Natural Science Foundation of China (No. 51632002, 51572108, 11634004, 11104103, 11774121), the Program for Changjiang Scholars and Innovative Research Team in University (No. IRT_15R23), the 111 Project (No. B12011), and the National Fund for Fostering Talents of Basic Science (No. J1103202). Parts of the calculations were performed in the High Performance Computing Center (HPCC) of Jilin University.

\section{References}

1 F. B. Tian, J. H. Wang, Z. He, Y. M. Ma, L. C. Wang, T. Cui, C. B. Chen, B. B. Liu and G. T. Zou, Superhard Semiconducting $\mathrm{C}_{3} \mathrm{~N}_{2}$ Compounds Predicted Via FirstPrinciples Calculations, Phys. Rev. B: Condens. Matter, 2008, 78, 235431.

2 D. D. Liu, M. G. Yao, Q. J. Li, W. Cui, B. Zou, T. Cui, B. B. Liu, B. Sundqvist and T. Wågberg, High Pressure and High Temperature Induced Polymerization of $\mathrm{C}_{60}$ Nanotubes, CrystEngComm, 2011, 13, 3600-3605.

3 D. Li, K. Bao, F. B. Tian, Z. W. Zeng, Z. He, B. B. Liu and T. Cui, Lowest Enthalpy Polymorph of Cold-Compressed Graphite Phase, Phys. Chem. Chem. Phys., 2012, 14, 43474350.

4 X. L. Wang, F. B. Tian, L. C. Wang, T. Cui, B. B. Liu and G. T. Zou, Structural Stability of Polymeric Nitrogen: A First-Principles Investigation, J. Chem. Phys., 2010, 132, 024502.

5 F. M. Gao, J. L. He, E. D. Wu, S. M. Liu, D. L. Yu, D. C. Li, S. Y. Zhang and Y. J. Tian, Hardness of Covalent Crystals, Phys. Rev. Lett., 2003, 91, 015502.

6 L. J. Zhang, Y. C. Wang, J. Lv and Y. M. Ma, Materials Discovery at High Pressures, Nature Reviews Materials, 2017, 2, 17005.

7 R. Freer, The Physics and Chemistry of Carbides, Nitrides and Borides, 1990.

8 H. O. Pierson, Handbook of Refractory Carbides and Nitrides, 1996.

9 J. C. Crowhurst, A. F. Goncharov, B. Sadigh, C. L. Evans, P. G. Morrall, J. L. Ferreira and A. J. Nelson, Synthesis and Characterization of the Nitrides of Platinum and Iridium, Science, 2006, 311, 1275-1278.

10 U. Shah, S. Chackalamannil, A. K. Ganguly, M. Chelliah, S. Kolotuchin, A. Buevich and A. Mcphail, Synthesis of Novel Transition Metal Nitrides $\operatorname{IrN}_{2}$ and $\mathrm{OsN}_{2}$, Phys. Rev. Lett., 2006, 96, 155501.
11 J. Q. Qin, D. W. He, J. H. Wang, L. M. Fang, L. Lei, Y. J. Li, J. Hu, Z. L. Kou and Y. Bi, Is Rhenium Diboride a Superhard Material?, Adv. Mater., 2008, 20, 4780-4783.

12 M. Xie, R. Mohammadi, Z. Mao, M. M. Armentrout, A. Kavner, R. B. Kaner and S. H. Tolbert, Exploring the High-Pressure Behavior of Superhard Tungsten Tetraboride, Phys. Rev. B: Condens. Matter, 2012, 85, 341-344.

13 Q. F. Gu, G. Krauss and W. Steurer, Transition Metal Borides: Superhard Versus Ultra-Incompressible, Adv. Mater., 2008, 20, 3620-3626.

14 X. Y. Cheng, W. Zhang, X. Q. Chen, H. Y. Niu, P. T. Liu, K. Du, G. Liu, D. Z. Li, H. M. Cheng and H. Q. Ye, Interstitial-Boron Solution Strengthened $\mathrm{WB}_{3+X}$, Appl. Phys. Lett., 2013, 103, 171903.

15 M. Wang, Y. W. Li, T. Cui, Y. M. Ma and G. T. Zou, Origin of Hardness in $\mathrm{WB}_{4}$ and Its Implications for $\mathrm{ReB}_{4}, \mathrm{TaB}_{4}, \mathrm{MoB}_{4}$, $\mathrm{TcB}_{4}$, and $\mathrm{OsB}_{4}$, Appl. Phys. Lett., 2008, 93, 101905.

16 J. J. Gilman, R. W. Cumberland and R. B. Kaner, Design of Hard Crystals, Int. J. Refract. Met. Hard Mater., 2006, 24, 1-5.

17 P. Wanjara, R. A. L. Drew, J. Root and S. Yue, Evidence for Stable Stoichiometric $\mathrm{Ti}_{2} \mathrm{C}$ at the Interface in $\mathrm{TiC}$ Particulate Reinforced Ti Alloy Composites, Acta Mater., 2000, 48, 1443-1450.

18 C. H. De Novion and J. P. Landesman, Order and Disorder in Transition Metal Carbides and Nitrides: Experimental and Theoretical Aspects, Pure Appl. Chem., 2009, 57, 1391-1402.

19 V. N. Lipatnikov, L. V. Zueva, A. I. Gusev and A. Kottar, Disorder-Order Phase Transformations and Electrical Resistivity of Nonstoichiometric Titanium Carbide, Phys. Solid State, 1998, 40, 1211-1218.

20 L. V. Zueva and A. I. Gusev, Effect of Nonstoichiometry and Ordering on the Period of the Basis Structure of Cubic Titanium Carbide, Phys. Solid State, 1999, 41, 1032-1038.

21 G. Amirthan, K. Nakao, M. Balasubramanian, H. Tsuda and S. Mori, Influence of $\mathrm{N}$ and $\mathrm{Fe}$ on $\alpha$-Ti Precipitation in the in Situ TiC-Titanium Alloy Composites, J. Mater. Sci., 2011, 46, 1103-1109.

22 M. B. Ivanov, S. S. Manokhin, D. A. Nechaenko and Y. R. Kolobov, Features of the Crystal Structure of Disperse Carbides in Alpha Titanium, Russ. Phys. J., 2011, 54, 749-755.

23 Y. F. Yang, H. Y. Wang, J. G. Wang and Q. C. Jiang, Lattice Parameter and Stoichiometry of $\mathrm{TiC}_{x}$ Produced in Alloyed Ti-C Systems by Self-Propagating High-Temperature Synthesis, J. Am. Ceram. Soc., 2008, 91, 3813-3816.

24 D. A. Aksyonov, A. G. Lipnitskii and Y. R. Kolobov, Ab Initio Study of Ti-C Precipitates in Hcp Titanium: Formation Energies, Elastic Moduli and Theoretical Diffraction Patterns, Comput. Mater. Sci., 2012, 65, 434-441.

25 C. Jiang and W. S. Jiang, Pressure-Composition Phase Diagram of Ti-C from First Principles, Phys. Status Solidi B, 2014, 251, 533-536.

26 A. I. Gusev, Phase Equilibria, Phases and Compounds in the TiC System, Russ. Chem. Rev., 2002, 71, 439-463.

27 P. A. Korzhavyi, L. V. Pourovskii, H. W. Hugosson, A. V. Ruban and B. Johansson, Ab Initio Study of Phase Equilibria in $\mathrm{TiC}_{(x)}$, Phys. Rev. Lett., 2001, 88, 015505. 
28 X. X. Yu, C. R. Weinberger and G. B. Thompson, Ab Initio Investigations of the Phase Stability in Group IVB and VB Transition Metal Carbides, Comput. Mater. Sci., 2016, 112, 318-326.

29 E. M. Fryt, Defect Mobility in $\mathrm{TiC}_{1-X}$ at High Temperatures, Solid State Ionics, 1997, 101-103, 437-443.

30 D. W. Zhou, X. L. Jin, X. Meng, G. Bao, Y. M. Ma, B. B. Liu and T. Cui, Ab Initio Study Revealing a Layered Structure in Hydrogen-Rich $\mathrm{KH}_{6}$ under High Pressure, Phys. Rev. B: Condens. Matter, 2012, 86, 6335.

31 Y. M. Ma, M. Eremets, A. R. Oganov, Y. Xie, I. Trojan, S. Medv-edev, A. O. Lyakhov, M. Valle and V. Prakapenka, Transparent Dense Sodium, Nature, 2009, 458, 182-185.

32 D. F. Duan, Y. X. Liu, F. B. Tian, D. Li, X. L. Huang, Z. L. Zhao, H. Y. Yu, B. B. Liu, W. J. Tian and T. Cui, Pressure-Induced Metallization of Dense $\left(\mathrm{H}_{2} \mathrm{~S}\right)_{2} \mathrm{H}_{2}$ with High- $\mathrm{T}_{\mathrm{c}}$ Superconductivity, Sci. Rep., 2014, 4, 06968.

33 A. R. Oganov and C. W. Glass, Crystal Structure Prediction Using $\mathrm{Ab}$ Initio Evolutionary Techniques: Principles and Applications, J. Chem. Phys., 2009, 124, 201-419.

34 A. R. Oganov, A. O. Lyakhov and M. Valle, How Evolutionary Crystal Structure Prediction Works-and Why, Acc. Chem. Res., 2011, 44, 227-237.

35 A. O. Lyakhov, A. R. Oganov, H. T. Stokes and Q. Zhu, New Developments in Evolutionary Structure Prediction Algorithm Uspex, Comput. Phys. Commun., 2013, 184, 11721182.

36 J. P. Perdew, K. Burke and M. Ernzerhof, Generalized Gradient Approximation Made Simple, Phys. Rev. Lett., 1996, 77, 3865-3868.

37 K. Parlinski, Z. Q. Li and Y. Kawazoe, First-Principles Determination of the Soft Mode in Cubic $\mathrm{ZrO}_{2}$, Phys. Rev. Lett., 1997, 78, 4063-4066.

38 A. Togo, F. Oba and I. Tanaka, First-Principles Calculations of the Ferroelastic Transition between Rutile-Type and $\mathrm{CaCl}_{2}$-Type $\mathrm{SiO}_{2}$ at High Pressures, Phys. Rev. B: Condens. Matter, 2008, 78, 134106.

39 Z. J. Wu, E. J. Zhao, H. P. Xiang, X. F. Hao, X. J. Liu and J. Meng, Publisher's Note: Crystal Structures and Elastic Properties of Superhard $\mathrm{IrN}_{2}$ and $\mathrm{IrN}_{3}$ from First Principles, Phys. Rev. B: Condens. Matter, 2007, 76, 054115.

40 R. Hill, The Elastic Behaviour of a Crystalline Aggregate, Proc. Phys. Soc., London, Sect. A, 1952, 65, 349-354.

41 F. Gao, J. He, E. Wu, S. Liu, D. Yu, D. Li, S. Zhang and Y. J. Tian, Hardness of Covalent Crystals, Phys. Rev. Lett., 2003, 91, 015502.

42 M. D. Segall, R. Shah, C. J. Pickard and M. C. Payne, Population Analysis of Plane-Wave Electronic Structure Calculations of Bulk Materials, Phys. Rev. B: Condens. Matter, 1996, 54, 16317.

43 M. D. Segall, P. J. D. Lindan, M. J. Probert, C. J. Pickard, P. J. Hasnip, S. J. Clark and M. C. Payne, First-Principles Simulation: Ideas, Illustrations and the Castepcode, $J$. Phys.: Condens. Matter, 2002, 14, 2717-2744.

44 D. Vanderbilt, Soft Self-Consistent Pseudopotentials in a Generalized Eigenvalue Formalism, Phys. Rev. B: Condens. Matter, 1990, 41, 7892-7895.
45 F. P. Miller, A. F. Vandome and J. Mcbrewster, Materials Studio, 2010.

46 V. L. Deringer, A. L. Tchougréeff and R. Dronskowski, Crystal Orbital Hamilton Population (Cohp) Analysisas Projected from Plane-Wave Basis Sets, J. Phys. Chem. A, 2011, 115, 5461-5466.

47 S. Maintz, V. L. Deringer, A. L. Tchougréeff and R. Dronskowski, Analytic Projection from Plane-Wave and Paw Wavefunctions and Application to Chemical-Bonding Analysis in Solids, J. Comput. Chem., 2013, 34, 2557-2567.

48 M. I. Mcmahon and R. J. Nelmes, High-Pressure Structures and Phase Transformations in Elemental Metals, Chem. Soc. Rev., 2006, 35, 943-963.

49 D. A. Andersson, P. A. Korzhavyi and B. Johansson, FirstPrinciples Based Calculation of Binary and Multicomponent Phase Diagrams for Titanium Carbonitride, Calphad, 2008, 32, 543-565.

50 H. J. Seifert, H. L. Lukas and G. Petzow, Thermodynamic Optimization of the Ti-C System, J. Phase Equilib., 1996, 17, 24-35.

51 H. Goretzki, Neutron Diffraction Studies on TitaniumCarbon and Zirconium-Carbon Alloys, Phys. Status Solidi B, 1967, 20, 141-143.

52 A. N. Christensen, R. Hämäläinen, U. Turpeinen, A. F. Andresen, O. Smidsrød, C. O. Pontchour, P. Phavanantha, S. Pramatus, B. N. Cyvin and S. J. Cyvin, The Temperature Factor Parameters of Some Transition Metal Carbides and Nitrides by Single Crystal X-Ray and Neutron Diffraction, Acta Chem. Scand., 1978, 32, 89-90.

53 L. P. Ding, P. Shao, F. H. Zhang, X. F. Huang and T. L. Yuan, Structure, Relative Stabilities, Physical Properties, and Hardness of Osmium Carbides with Various Stoichiometries: First-Principle Investigations, J. Phys. Chem. C, 2015, 119, 21639-21648.

54 Q. Tao, X. P. Zhao, Y. L. Chen, J. Li, Q. Li, Y. M. Ma, J. J. Li, T. Cui, P. W. Zhu and X. Wang, Enhanced Vickers Hardness by Quasi-3d Boron Network in $\mathrm{MoB}_{2}, R S C A d v ., 2013,3$, 18317-18322.

55 S. P. Zhao, Y. L. Yang, J. Lu, W. Wu, S. Sun, X. Li, X. L. Zhao, S. X. Cao, J. C. Zhang and W. Ren, Carbon-Rich Superhard Ruthenium Carbides from First-Principles, Mater. Des., 2017, 117, 353-362.

56 Y. W. Li, J. Hao and Y. Xu, Predicting Hard Metallic Osmium-Carbon Compounds under High Pressure, Phys. Lett. A, 2012, 376, 3535-3539.

57 C. M. Sung and M. F. Tai, Reactivities of Transition Metals with Carbon: Implications to the Mechanism of Diamond Synthesis under High Pressure, Int. J. Refract. Met. Hard Mater., 1997, 15, 237-256.

58 R. Chang and L. J. Graham, Low-Temperature Elastic Properties of ZrC and TiC, J. Appl. Phys., 1966, 37, 3778-3783.

59 R. C. Weast, M. J. Astle and W. H. Beyer, Handbook of Chemistry and Physics, CRC Press, Inc, 1996.

60 P. Ravindran, L. Fast, P. A. Korzhavyi, B. Johansson, J. Wills and O. Eriksson, Density Functional Theory for Calculation of Elastic Properties of Orthorhombic Crystals: Application to $\mathrm{TiSi}_{2}$, J. Appl. Phys., 1998, 84, 4891-4904. 
61 A. Marmier, Z. A. D. Lethbridge, R. I. Walton, C. W. Smith, S. C. Parker and K. E. Evans, Elam: A Computer Program for the Analysis and Representation of Anisotropic Elastic Properties, Comput. Phys. Commun., 2010, 181, 2102-2115.

62 M. M. Zhong, X. Y. Kuang, Z. H. Wang, P. Shao, L. P. Ding and X. F. Huang, Phase Stability, Physical Properties, and Hardness of Transition-Metal Diborides $\mathrm{MB}_{2}(\mathrm{M}=\mathrm{Tc}, \mathrm{W}$, Re, and Os): First-Principles Investigations, J. Phys. Chem. C, 2013, 117, 10643-10652.

63 A. Simunek and J. Vackar, Hardness of Covalent and Ionic Crystals: First-Principle Calculations, Phys. Rev. Lett., 2006, 96, 085501.
64 R. A. Andrievski, Superhard Materials Based on Nanostructured High-Melting Point Compounds: Achievements and Perspectives, Int. J. Refract. Met. Hard Mater., 2001, 19, 447-452.

65 G. Henkelman, A. Arnaldsson and H. Jónsson, A Fast and Robust Algorithm for Bader Decomposition of Charge Density, Comput. Mater. Sci., 2006, 36, 354-360.

66 A. D. Becke and K. E. Edgecombe, A Simple Measure of Electron Localization in Atomic and Molecular Systems, $J$. Chem. Phys., 1990, 92, 5397-5403.

67 X. Q. Chen, H. Y. Niu, D. Z. Li and Y. Y. Li, Modeling Hardness of Polycrystalline Materials and Bulk Metallic Glasses, Intermetallics, 2011, 19, 1275-1281. 